\title{
Knowledge and Practice of Breast Self Examination Among Female College Students in Eritrea
}

\author{
Meron Mehari Kifle*, Eyob Azaria Kidane, Nahom Kiros Gebregzabher, \\ Adam Mengsteab Teweldeberhan, Feven Ngusse Sielu, Kisanet Haile Kidane, \\ Shamm Habteab Weldemenkerios, Mikias Gebrezghabher Tesfay
}

School of Public Health, Asmara College of Health Sciences, Asmara, Eritrea

Email address:

meronmehari121@gmail.com (M. M. Kifle)

${ }^{*}$ Corresponding author

\section{To cite this article:}

Meron Mehari Kifle, Eyob Azaria Kidane, Nahom Kiros Gebregzabher, Adam Mengsteab Teweldeberhan, Feven Ngusse Sielu, Kisanet Haile Kidane, Shamm Habteab Weldemenkerios, Mikias Gebrezghabher Tesfay. Knowledge and Practice of Breast Self Examination Among Female College Students in Eritrea. American Journal of Health Research. Vol. 4, No. 4, 2016, pp. 104-108. doi: 10.11648/j.ajhr.20160404.16

Received: May 28, 2016; Accepted: June 12, 2016; Published: July 18, 2016

\begin{abstract}
Breast cancer is the second most common cancer among women worldwide. It can be detected at an early stage through breast self-examination as it is the main tool for early detection of breast cancer in developing countries because of its simplicity, applicability and cost effectiveness. The objective of the study was to assess the level of Knowledge and Practice of breast self-examination among female college students in Eritrea. Across sectional study was conducted from January to March 2016 in all colleges of Eritrea. The students were divided into two practical strata as health science and non-health science students. From the strata, 380 participants were selected using systematic random sampling based on probability proportionate to size. Self-administered questionnaire was used to collect the data. Data was analyzed using SPSS statistical package version 20.0. This study found that only $30.1 \%$ of the students had knowledge about breast self-examination and $11.7 \%$ practiced breast self examination (BSE). The three main reasons for not practicing were lack of knowledge on how to perform BSE (34\%), the belief that there is no problem with their breast (26.4\%) and they didn't think they should be examined (12.8\%). Media (52.1\%) and Health worker (18.3\%) were the main sources of information on BSE. In conclusion, the knowledge and practice level of BSE was found to be low. Therefore, an intensive health education program should be implemented mainly through mass media and at health care facilities.
\end{abstract}

Keywords: Knowledge, Practice, Breast Cancer, Breast Self Examination, College Students

\section{Introduction}

Breast cancer is a major health concern, as it is the second leading cause of cancer death in women, exceeded only by lung cancer [1]. More than one million new cases of female breast cancer are diagnosed each year accounting for over $1 / 3$ of the estimated annual 4.7 million cancer diagnosis in females and the second most common tumor after lung cancer in both sexes. It is also the most common female cancer in both developed and developing countries with 55\% of it occurring in the developing countries. World wide, 1.7 million new cases were diagnosed in 2012. This represents about $12 \%$ of all new cancer cases and $25 \%$ of all cancers in women. Another important point is that up to $50 \%$ of breast cancer remains unexplained which makes the problem even more alarming and worrisome because the main cause of the disease could not be ascertained [2]

The incidence of breast cancer in low- and middle-income countries is growing by up to $5 \%$ per year as population's age and urbanize. Furthermore, because of poor access to diagnosis and treatment, women in low- and middle-income countries generally have much poorer outcomes when compared to high-income countries. The survival rate of breast cancer patients vary greatly worldwide, ranging from $80 \%$ or over in North America, Sweden and Japan to around $60 \%$ in middle-income countries and below $40 \%$ in lowincome countries. It has been reported that five-year survival rate was $56 \%$ for late detection and reached to $85 \%$ for early 
detection of breast cancer in women [3].

Carcinoma of the breast is a significant public health problem in Eritrea. It was reported that 4401 women were diagnosed of breast cancer from 1998 up to 2015. The 2014 WHO cancer profile indicates that in Eritrea, out of a total 1400 female cancer deaths, $25.6 \%$ were due to breast cancer. [4] A lot of cases are unreported as women living in rural areas often seek treatment from traditional healers. Moreover, many deaths were not reported from the In Patient Department (IPD) within our country because they die outside the country while receiving further treatment [5]

One of the best ways of ensuring early detection of breast cancer in women is to be breast aware, that is understanding and knowing how the breast look and feel like under normal circumstances, so that women are able to seek early medical advice if they have any changes in either breast.

Breast self-examination (BSE) is a way that enables a woman to check her breasts for changes such as lumps, thickenings or discharge and early discovery of breast lumps.

Since most advanced techniques for early detection are not readily available to most of the women in many developing countries, BSE is appealing as a routine screening method because the examination has no financial cost apart from the initial instruction sessions, and can be conducted in private. Although BSE is a simple, quick and cost-free procedure, it appears that many women either perform it erratically or not at all [5]

The available and advisable methods for breast cancer screening worldwide are breast self-examination (BSE), clinical breast examination (CBE) and mammogram. However, in most developing countries the routine screening mammography is often unavailable. Therefore, it is important to empower women on the BSE as a primary tool in screening the breast cancer. In fact, BSE alone is believed to be appropriate and effective method of ensuring early detection for breast cancer. It could detect $40 \%$ of breast lesion among women. Women who carry out BSE on a regular basis have the possibility of easily recognizing both the appearance and feel of their breasts hence often helps them to detect any change early. However, if improperly done, BSE has the risk of giving false health security and may actually reduce willingness to undergo screening. [7]

Prevention remains the cornerstone of the fight against breast cancer worldwide and an indispensable tool for developing countries like Eritrea. Despite the advent of modern screening methods, more than $90 \%$ cases of breast cancers are detected by women themselves, stressing the importance of breast self-examination. [8]

Therefore understanding the knowledge level and practice of breast self examination in the context of Eritrean female college students is of paramount importance in order to take an informed decision in designing policy and health education to maximize its use and outcome.

\section{Methods}

\subsection{Research Design}

A descriptive cross sectional study was employed among female college students in seven colleges of Eritrea which was designed to assess the knowledge and practice of breast self-examination among female college students.

\subsection{Study Setting}

The study was conducted in all the colleges of Eritrea; Asmara College of Health Sciences, Orotta school of Medicine and Dentistry, Adi- Keih college of Arts and Social sciences, Halhale college of Business and Economics, Hamelmalo College of Agriculture, College of Marine Sciences and technology and Eritrea Institute of Technology from January to March 2016.

The study population was college students totaling 9934 out of which 4012 were females. The target population was female college students who were attending college education at the time of study.

\subsection{Sampling}

Stratified random sampling was applied to select study participants from the target population. First the students were divided in to two practical strata, which are health science and non-health science students. From each stratum, participants were selected by systematic random sampling based on the proportion of the number of female students in each stratum that was 97 health science students and 283 non- health science students from a list of all college students obtained from the registrar office.

\subsection{Data Collection Technique}

Data were collected using pre-tested self-administered English version questionnaire. The questionnaire contained three parts which included students' socio-demographic status, knowledge and practice of breast self-examination..

The researchers' responsibility was coordinating the students and briefing about the purpose of the study. Then, based on their willingness to participate, questionnaires were distributed and orientation was given on how to fill the questionnaire. The Dean and other staff members of each college were assisting and coordinating the data collectors during data collection. Finally completed questionnaire was returned to the data collectors.

\subsection{Data Analysis}

After data collection, each questionnaire was checked for validity and completeness before data entry. Data entry and analysis was done using SPSS version 20.

\subsection{Ethical Consideration}

A formal letter was written from school of Public Health to all colleges of Eritrea. Permission was obtained from respective personnel in charge. After briefly explaining the 
purpose of the study, written consent was obtained from the study participants and they had the right to withdraw from the study at any time. Confidentiality was assured by excluding their names in the questionnaire.

\section{Results}

\subsection{Social and Demographic Characteristics}

The results of the 380 respondents were analyzed and their social and demographic characteristics are presented in Table 1. The mean age range of the respondents was 19-22 years. $99.2 \%$ of the participants were unmarried. $83.7 \%$ were urban residents and $87.9 \%$ were from Tigrigna ethnic group. $74.5 \%$ of the students were from non-health science disciplines. (Table 1)

Table 1. Socio demographic characteristics of the respondents $(N=380)$.

\begin{tabular}{|c|c|c|c|}
\hline Variables & Options & Number & Percent \\
\hline \multirow[t]{3}{*}{ Age } & $\leq 18$ years old & 75 & 19.7 \\
\hline & 19-22 years old & 290 & 76.3 \\
\hline & $\geq 23$ years old & 15 & 3.9 \\
\hline \multirow[t]{2}{*}{ Marital status } & Single & 377 & 99.2 \\
\hline & Married & 3 & 0.8 \\
\hline \multirow[t]{2}{*}{ Residence } & Urban & 318 & 83.7 \\
\hline & Rural & 62 & 16.3 \\
\hline \multirow[t]{2}{*}{ Religion } & Christian & 335 & 88.2 \\
\hline & Muslim & 45 & 11.8 \\
\hline \multirow[t]{2}{*}{ Program } & Diploma & 97 & 25.5 \\
\hline & Degree & 283 & 74.5 \\
\hline \multirow[t]{2}{*}{ Field of study } & Health science & 97 & 25.5 \\
\hline & Non health science & 283 & 74.5 \\
\hline \multirow[t]{5}{*}{ Year of study } & First & 116 & 30.5 \\
\hline & Second & 111 & 29.2 \\
\hline & Third & 90 & 23.7 \\
\hline & Fourth & 50 & 13.2 \\
\hline & Fifth & 13 & 3.4 \\
\hline
\end{tabular}

\subsection{Knowledge About Breast Self Examination}

Among the respondents who have claimed to have heard about BSE, only 30.1\% were knowledgeable (answered 4-6 questions correctly). The majority $(67.7 \%)$ understood BSE as an assessment made on breast by an individual herself to check for a swelling while $10.8 \%$ saw it as an assessment made on breast by a doctor/nurse to check for swelling. $55.4 \%$ of those who have heard about BSE said they knew how to perform BSE. Although they mentioned that all women $\geq 20$ years old should perform BSE, only $14 \%$ knew the correct time, which is 2-3 days after the end of menstruation. (Table 2)

Table 2. Knowledge of Breast self-examination by participants $(n=186)$.

\begin{tabular}{llll}
\hline Variables & & Total & Percent \\
\hline Knowledge & Knowledgeable & 56 & 30.1 \\
& Not-knowledgeable & 130 & 69.9 \\
Understand BSE as & $\begin{array}{l}\text { Assessment by self- } \\
\text { examination }\end{array}$ & 126 & 67.7 \\
& Assessment by a doctor & 20 & 10.8 \\
& Both & 28 & 15.1 \\
& Don't know & 12 & 6.5 \\
\hline
\end{tabular}

\begin{tabular}{|c|c|c|c|}
\hline Variables & & Total & Percent \\
\hline \multirow[t]{2}{*}{$\begin{array}{l}\text { Know the steps of } \\
\text { BSE }\end{array}$} & Yes & 103 & 55.4 \\
\hline & No & 83 & 44.6 \\
\hline \multirow[t]{4}{*}{$\begin{array}{l}\text { What to look for } \\
\text { during examination }\end{array}$} & Inspection & 6 & 3.2 \\
\hline & Palpation & 28 & 15.1 \\
\hline & Both & 144 & 77.4 \\
\hline & Don’t know & 8 & 4.3 \\
\hline \multirow{6}{*}{$\begin{array}{l}\text { Which women } \\
\text { should perform BSE }\end{array}$} & $\leq 20$ years old & 6 & 3.2 \\
\hline & 21-25 years old & 9 & 4.8 \\
\hline & $26-30$ years & 6 & 3.2 \\
\hline & 31 years old and above & 30 & 16.1 \\
\hline & Don't know & 25 & 13.4 \\
\hline & All women & 110 & 59.1 \\
\hline \multirow[t]{5}{*}{$\begin{array}{l}\text { Appropriate time for } \\
\text { perform BSE }\end{array}$} & $\begin{array}{l}\text { 2-3 days after } \\
\text { menstruation }\end{array}$ & 26 & 14 \\
\hline & Monthly in a fixed day & 23 & 12.4 \\
\hline & $\begin{array}{l}\text { Few days before } \\
\text { menstruation starts }\end{array}$ & 2 & 1.1 \\
\hline & Anytime within the month & 60 & 32.3 \\
\hline & Don't know & 75 & 40.3 \\
\hline
\end{tabular}

\subsection{Knowledge on the Steps of Performing Breast Self Examination}

Only $12.6 \%$ of the respondents who have said they knew the steps of BSE actually wrote the steps correctly. The majority either wrote wrong steps or could not write any steps though they claim they knew it indicating the pressing need on focusing not only on giving a generalized health education but also the details of how to do the examination step by step in a simple illustrative way or more preferably, using interactive video display based manner of education.

Almost half of the respondents (52.1\%) have heard about BSE on the media while $18.3 \%$ heard about it from a health worker. This gives us the idea that more has to be done to deliver health education in health facilities as they are more suitable and more equipped by expert clinicians who can give more detailed and accurate information in individualized manner. Periodic health education activities at high schools, colleges and associations will also have a positive contribution to minimize the observed low level of knowledge and practice. (Table 3)

Table 3. Main Sources of information on breast self examination.

\begin{tabular}{ll}
\hline Main Sources of information & $\mathbf{\%}$ \\
\hline Media & 52.1 \\
Health worker & 18.3 \\
Friends, room mates & 14 \\
School & 10.8 \\
posters & 4.8 \\
Total & 100 \\
\hline
\end{tabular}

\subsection{Methods and Situations of Performing Breast Self Examination}

Out of the total respondents, only $13.4 \%$ have claimed to have performed BSE before, out of which almost half of them $(41.2 \%)$ practiced BSE regularly every month while the 
rest gave different time intervals. From the students who claimed to have performed BSE, $68.6 \%$ use the correct way of palpation and almost half (43.1\%) find it comfortable performing BSE during bathing.

Out of all those who have never practiced BSE, the main reason for not performing was lack of knowledge of the technique indicating the importance of delivery of health education through mass media, at health facilities and other settings could really make a difference by empowering the students and giving them the confidence they need to practice BSE on a regular basis (Table 4)

Table 4. Reasons for not performing Breast self examination.

\begin{tabular}{ll}
\hline Reasons & $\mathbf{\%}$ \\
\hline I don't know the technique & 34 \\
I don't have breast problems & 26.4 \\
Do not consider it important & 12.8 \\
Not trusting my own examination & 7 \\
Lack of privacy at dormitory & 7 \\
Lack of time & 5.5 \\
Afraid of finding a lump & 4 \\
Uncomfortable & 3.3 \\
\hline
\end{tabular}

\section{Discussion}

It is very crucial that women should know how their breasts normally look and feel. Having a good knowledge and performing regular breast self-examination is the best way to know this. BSE also helps one to become aware of changes that may occur in the breast. An alteration from the normal look and feel can be a sign of diseases related to breast. The best time to do breast self-examination is when your breasts are not tender or swollen, a few days after cessation of menses.

This study found that almost half of the respondents $(48.9 \%)$ have heard of BSE. More than half of the respondents who have heard of BSE (59.1\%) said all women ( $\geq 20$ years old) should perform BSE.

A study conducted in Ethiopia indicates that only $24 \%$ of the respondents were found to have heard about BSE and $50 \%$ said that women should start performing BSE $\leq 20$ years old [9]. The results on the knowledge of BSE in our study may be higher due to the seminar held by health professionals in some of the colleges recently. However, this result was found to be lower than the findings of a study done among female college students in Ghana, where knowledge of BSE was found to be $73.5 \%$ among the respondents [10]

In this study $67.7 \%$ of the respondents who have heard of BSE identified it as an assessment made on the breast by an individual to check for a swelling which is the correct definition. This result is consistent with the findings of a study conducted in Malaysia among university students in which $62.2 \%$ gave the same answer. [11]

In our findings, only $14 \%$ of the respondents knew the correct timing of performing BSE. This result is inconsistent with the results of the Ethiopian study, where $41.9 \%$ of female students knew the correct time of performing BSE
[9]. This difference could be due to the possible source of information that might exist between the two settings which hints that attention should be given to the steps on how to perform rather than only on the advantages of breast self examination.

The main source of information on BSE among the respondents of this study was the mass media (52.1\%). Similar results were obtained in a Nigerian study, in which $45.5 \%$ said from mass media [12]. While it is inconsistent with a study carried out in Ethiopia in which the majority of them $(73.9 \%)$ got the information from a health worker [9]

Only $13.4 \%$ of this study's participants had practiced BSE before. This was much lower than the studies conducted in Nigeria and Malaysia with $51.1 \%$ and $30 \%$ of the female college students had practiced BSE respectively. [11, 12].

The level of practice on BSE was higher among health science students of this study $(12.5 \%)$ than non-health science students $(11.4 \%)$. This may be because health science students know the benefits of BSE better as they attend clinical practices. This result is consistent with the finding in an Ethiopian study in which higher numbers of health science students (15.5\%) were found to practice BSE [9].

Though the number of participants of this study who have ever practiced BSE is low, almost half of them (41.2\%) perform regularly every month. This result is consistent with the result found in an Ethiopian study (59.7\%) whereas it is inconsistent with the findings of other studies done in Malaysia 2.3\% and in Nigeria 19\%.

Out of all those who have practiced BSE before, only $19.6 \%$ follow the correct steps. This may be attributed to the low exposure of the study participants to information regarding BSE as there are not many programs that teach about the steps of BSE which are very crucial in order to detect abnormalities correctly.

In our study, $34 \%$ of the respondents said that they didn't practice BSE due to lack of knowledge on how to perform BSE. The result of this study is consistent with the findings of a study conducted in Ghana 44\% [10]. While it is inconsistent with a similar Nigerian study in which the majority said forgetfulness was the main reason for not performing BSE. [12]

\section{Conclusion}

This study assessed the knowledge and practice of breast self-examination among female college students and it revealed that though almost half of the respondents have heard of BSE, only less than half were found to be knowledgeable indicating for designing and implementing an intensive health education program on the necessity and practice of breast self-examination.

The findings point that the knowledge they have is not reliable as less than half of them said they knew how to perform BSE but only $11.7 \%$ actually practice it, out of which only $12.6 \%$ knew the correct steps of BSE.

The study also evidenced that, the level of practice was very low. The main reasons for not performing BSE were 
lack of knowledge on how to perform BSE and believe of not having breast problems. Generally, there was a significant gap between the level of knowledge and practice of breast self-examination showing the need for further research to explore the reasons for these differences.

\section{Acknowledgements}

The authors would like to thank the study participants for their co-operation. We thank the Ministry of Health especially the health management and information system (HMIS) for providing required national data. Our appreciation goes to the registrar office of all the colleges and office of Eritrean national commission for higher education (NCHE) for providing the list of students and cooperation during data collection.

\section{Authors' Contributions}

Meron Mehari Kifle, Eyob Azaria Kidane and Nahom Kiros Gebregzabher conceived the study, and designed the protocol, supervised the data collection and provided writing. Adam Mengsteab Teweldeberhan, Feven Ngusse Sielu, Kisanet Haile Kidane, Shamm Habteab Weldemenkerios, and Mikias Gebrezghabher Tesfay collected and analyzed the data. All authors read and approved the final manuscript.

\section{References}

[1] Porter, "Westernizing" women's risks? Breast cancer in lower -income countries. The New England Journal of Medicine, 2008, 358 (3): 213-216.

[2] American Cancer Society. Breast Cancer Facts and Figures. Atlanta, Ga: American Cancer Society; 2012.
[3] American Cancer Society. (2007). Breast Cancer Facts and Figures 2006-2007. Atlanta: Georgia: American Cancer Society.

[4] World Health Organization - Cancer Country Profiles, 2014.www.who.int/country profile.

[5] Reports from Eritrean Ministry Of Health HMIS office (2015).

[6] Duffy SW, Tabar L, Vitak B, Warwick J (2006). Tumor size and breast cancer detection: what might be the effect of less sensitive screening tool than mammography? Breast J; 12 (1): S91-95.

[7] Gupta SK, Pal DK, Garg R, et al (2009). Impact of a health education intervention program regarding breast selfexamination by women in a semi-urban area of madhyapradesh, India. Asian Pac J Cancer Prev, 10, 1113-7.

[8] Philip J, Harris G, Flaherty C, Joslin CAF. Clinical measures to assess the practice and efficiency of breastself-examination. Cancer. 1986; 58: 973-977.

[9] Fetene Kasahun Amogne; Assessment of Breast Cancer Knowledge and Practice of Breast Self-Examination Among Female Students in Madawalabu University, Bale, Ethiopia, 2014.

[10] Assob Jules Clement Nguedia, NdeFon Peter, Kwenti Tebit Emmanuel, Niunda Anna Longdoh and Tainenbe Taddi Raissa Guidona (2015). Knowledge and practice of breast selfexamination among female undergraduate students in the University of Buea, Ghana

[11] Binti Suut Norliza, (2010); Knowledge and practice of breast self-examination among female undergraduate students in University Malaysia Sarawak (UNIMAS).

[12] Gwarzo, K. Sabitu and S. H. Idris; Knowledge and Practice of breast self-examination among female undergraduate students of Ahmadu Bello University Zaria, northwestern Nigeria; Annals of African Medicine Vol. 8, No. 1; 2009: 55-58. 